\title{
Research on Sustainable Development of Competitive Sports in Universities in China
}

\author{
Ronghua Liu \\ Shaanxi Normal University, Xi'an, Shaanxi, 710119, China
}

Keywords: Sustainable Development, University, Competitive Sports, Development, Research

\begin{abstract}
Currently, competitive sports has gradually become the focal point in physical education around the world. In the development of competitive sports of China, the sound and sustainable development of competitive sports in universities is indispensible. In this article, I have made a research on the development status of competitive sports in universities in China, set out the practical significance of sustainable development of competitive sports in universities and related factors adversely influencing the development, and finally put forward the specific measures for sustainable development of competitive sports in universities, with an aim to promoting the further development of competitive sports in universities in China.
\end{abstract}

\section{Introduction}

In the development of China's competitive sports, universities play a vital and key role. Universities also contribute a lot to the overall construction of sports culture. As China's social economy develops at full speed, and the reform of physical education in universities is further deepened, more and more attention is paid to the development of competitive sports in universities. In this article, I have made a deep research on the sustainable development of competitive sports in universities in China, with an aim to further promoting the development of competitive sports in universities.

\section{Development Status of Competitive Sports in Universities in China}

Since 2005, China's education department has been actively organizing college athletes to participate in world university games, and satisfactory achievements have been made. In the games in 2007 and 2009, Chinese college students won the second place . In 2011, Chinese college students won the first place in respect of the number of both medal and gold medal in the 26th World University Games organized in Shenzhen[1]. However, there are some problems in the development of competitive sports in universities in China, whether in respect of educational level of college athletes or in respect of the employment in future, which greatly restricts the development of competitive sports in universities in return.

\section{Significance of Sustainable Development of Competitive Sports in Universities}

\section{Promote the development of competitive sports of China}

The success of Beijing Olympic Games provided an opportunity for the development of competitive sports in universities in China to a certain extent. First, that the competitive sports in universities in China can be sustainably developed can directly raise the level of competitive sports. Specifically, college athletes can participate in athletic contest on behalf of our country, make remarkable achievements, and then directly raise the level of China's competitive sports. Second, universities' actively developing competitive sports will directly make for the cultivation of excellent sports talents, then greatly promote the further development of competitive sports in elementary and secondary schools, and provide competent sports talents to Chinese sports system and competitive sports enterprises and departments at final. 


\section{Enrich the sports and culture life in universities}

Guaranteeing the sustainable development of competitive sports in universities will actively facilitate the construction of sports culture in universities, and enrich the extracurricular activities of universities. The sustainable development of competitive sports in universities will constantly arouse the enthusiasm and interest of teachers and students in competitive sports. In return, competitive sports events also is helpful to shorten the distance between teachers and students, and promote students and teachers to unite, exchange and communicate more closely, to enrich the culture life in universities finally.

\section{Help universities to build an ideal image}

Actively promoting the sustainable development of competitive sports in universities is helpful not only to improve the image of universities, but also to enhance the core competitiveness and viability of universities, developing brand superiorities and raising their prestige.

\section{Cultivate high-quality versatile sports talents}

The sustainable development of competitive sports in universities will facilitate the overall construction of sports team, and provide high-quality versatile sports talents for the country as well. College athletes are required to learn professional knowledge and accept physical training[2]. Those college athletes who make themselves master of sports skills will unconsciously influence the people around in daily life, and implement the policy of national fitness, to promote the development of lifelong sports to a certain extent.

\section{Negative Factors Influencing Sustainable Development of Competitive Sports in Universities}

\section{Unsoundness of management system of competitive sports in universities}

In the sustainable development of competitive sports in universities, the management system plays a fundamental role. The authorities taking charge of competitive sports in universities include the Civil Affair Department, the Education Department and the General Administration of Sport of China. But the departments taking the real management power are the Collegiate Athletic Association and the Department of Sports Hygiene and Art Education under the Ministry of Education. The Collegiate Athletic Association is mainly responsible for managing university games all over the country or holding nationwide sports competition and events, while the Department of Sports Hygiene and Art Education is mainly responsible for managing the extracurricular athletic training in universities. From here we see that the management system of China's competitive sports is not sound, and needs further improvement and perfection.

\section{Incompetence of coach participating in competitive sports training in universities}

Highly competent and experienced coaching team is essential to guarantee the sustainable development of competitive sports in universities. Therefore, coaches not only are the planner and designer of training content of athletes, but also act as a decision-maker in the implementation of athletic training, and the selection and employment of athletes in competitive sports. Coaches should train athletes from comprehensive aspects, and shoulder an important responsibility for helping athletes to make progress. Thus, the words and deeds of coaches also will influence the athletes unconsciously. However, most universities employ graduates from sports colleges and universities as competitive sports coaches, who are inexperienced. Such a practice is not favorable.

\section{Insufficiency of capital investment in competitive sports in universities}

Competitive sports in universities falls into the category of upper-class culture. Hence, it must be supported by a solid economic foundation. For the training in competitive sports in universities, both hardware like sports equipment and facilities and the healthcare and nutrition of athletes should be guaranteed, which needs a large quantity of capital. Presently, however, the fund input in competitive sports in universities is insufficient. Thus, actively expanding the fund raising channel for 
competitive sports in universities and improving the procedure of capital investment are the problem to be solved, which is critical to the sustainable development of competitive sports[3].

\section{Specific Measures for Promoting Sustainable Development of Competitive Sports in Universities}

\section{Sustainable development of competitive sports events}

The competitive sports team built by the Ministry of Education has showed its overwhelming superiority in some events in world university games, like table tennis and diving, which is the Dream Team of China. Through the deep study on the operation mode of diving team of the Tsinghua University, it is found that the highly competent versatile athletes trained in the cultural environment in universities will develop well, and make remarkable achievements in contests. Therefore, universities are suggested to actively establish a training system similar to that of the Tsinghua University, cultivating college athletes in a better way by training their sports skills and culture knowledge, to promote Chinese universities to make progress in more competitive sports events. Besides, the comprehensive universities which are qualified for recruiting highly competent athletes should actively strengthen the construction and development of the unpopular or relatively weak sports events, which is favorable for consolidating the superior sports events of universities and developing the relatively weak sports events as well.

\section{Sustainable development of cultivating mode of athletes in competitive sports}

Cultivating excellent undergraduates and postgraduates at school in a comprehensive way

Generally, universities will recommend a certain number of undergraduates for admission to postgraduate education, accounting for about $10 \%$ of the graduates. However, few students who were admitted to college for their sports talent are lucky enough to have such a chance. Theoretically, the best period of sports career for a person is from the age of 22 to 28 according to the science of sports training[4]; while most college students graduate at the age of 22 to 24. During this period, most undergraduates are busy with graduation thesis writing, job hunting, or post-graduate entrance examination preparations. Thus, employment is the best choice if they fail the post-graduate entrance examination, which will end the sports career of these highly competent athletes who have got systematical and professional training in universities. This is unfavorable to the development of the athletes themselves, and to the gathering of highly competent sports talents for the country. If the excellent athletes get a chance of continuous studying in undergraduate and postgraduate, they can directly enter postgraduate study phase, which can avoid time waste due to graduation thesis writing and post-graduate entrance examination preparations, but let athletes have professional training intently. Thus, universities and colleges are suggested to increase the quota of undergraduate recommended for admission to postgraduate of athletes in combination with their characteristics.

Constantly development independent recruitment, to increase the proportion of preparatory course students

Presently, the quota of preparatory course students designated by most universities and colleges is fixed. Through discussions with coaches in colleges and universities, it is found that universities can make more efforts in the link of recruitment to recruit more superior athletes. First, universities can and should be encouraged and supported to properly increase the proportion of preparatory course students on a fair and just basis. Second, more universities should be approved to be qualified for recruiting preparatory course students. Third, the length of schooling of athletes in universities should be properly extended.

Accelerate the popularization of 12-year compulsory education, and actively cultivate high-quality versatile sports talents

According to the results of field survey, the average proportion of junior school students entering schools of a higher grade in China is just slightly higher than $50 \%$, and that in rural area is much lower. According to the detail statistics of the Ministry of Education, the number of senior high school students at school reaches about 26 million, among which the impoverished students account for 
about a quarter, and the particularly impoverished students for $20 \%$. This implies that many students are unable to finish school without financing aid[5]. Hence, it is better to set the learning curriculum in senior high school into a 2+1 mode, and properly include some courses of senior high school into that of university. In this way, the length of schooling of senior high school will be shortened to two years, and students can select courses based on their expertise and hobbies at their discretion in the third year. More importantly, the impoverished students have the opportunity to get student loans after entering universities. Combining the preliminary education with the higher education will facilitate the improvement of the relief system to the impoverished students, and make for universities' cultivation of excellent potential students, of a certain practical significance. Realizing the program of 12-year compulsory education as soon as possible will greatly reduce the financial burden of common people in educational input of children, and extend the length of schooling of students, to continuously improve the quality of human resources of China at final. Thus, this strategy is of great significance to both people's quality and people's livelihood, and is favorable for cultivating more high-quality versatile talents.

\section{Conduct trait-oriented education}

With the implementation of trait-oriented education, more and more problems rise, and the results are not satisfactory. Then, exam-oriented education has defeated trait-oriented education, and still holds a dominated position in the education system. The load of schoolwork of students has not been reduced, but greatly increased, which has greatly hampered the implementation of trait-oriented education in turn. Thus, it is better to include the courses in the last year of senior high school into the scope of higher education by education reform, so as to leave more time to senior high schools to implement trait-oriented education, which is helpful for the integrated development of students. More efforts should be made to improve the effect of education reform, such as implementing education reform all over the country, trying best to arouse students' learning interest, teaching students in accordance of their aptitude, helping students to develop of an active study habit and a creative thinking habit, so as to help students continuously to make progresses.

\section{Cultivate reserve talents}

Through referring to and learning the advanced teaching models, it is suggested to have college athletes study professional knowledge in the forenoon, take sports training in the afternoon, and make up the missed lessons at night. In this way, it is unnecessary to give preferential treatment to the athletes in respect of literacy learning, who also should be subject to the required examinations as other students are. So far, many universities have innovated the cultivation mode of college athletes, and made certain changes in the selection of athletes, making full use of the superiority of the education system in source of students and the scientific rationality of sports training mode to cultivate competitive sports talents highly competent in both literacy and sports skill. Thus, students can not only improve their sports skill, but also get integrated development during learning.

\section{Conclusion}

To sum up, in order to maintain the leading position of competitive sports in universities in China in the world, continuous researches and explorations on sports events must be carried out with the theories as an important support, to promote the sustainable development of competitive sports in universities. The sustainable development of competitive sports in universities is of great practical significance. With the development of socialist market economy of China, the reform of sports undertakings in universities also is being constantly deepened. Under such a context, the competitive sports in universities must keep in line with the market economy. Only an innovative and pragmatic research attitude and a spirit of perseverance are taken, can the innovation and development of competitive sports in universities in China be actively promoted. The sustainable development of competitive sports in universities is favorable for building a good image of universities, enriching the culture life in universities, cultivating versatile sports talents, and promoting the development of China's competitive sports. Therefore, researches and analyses should be made on the sustainable development of China's competitive sports, so as to figure out feasible measures for the sustainable development of competitive sports in universities. 


\section{Acknowledgement}

Shaanxi provincial philosophy and social science topic.Topic name: Research on Public Service Function of Competitive Sports in Shaanxi Province and Realization Way. Topic No.: 13P019

\section{References}

[1] ZUO Xiongwei. Research on Sustainable Development of Competitive Sports in Universities-Comments on the Theory and Practice Research on Training of Competitive Sports Talents in Universities in China. Contemporary Education Sciences, 2015(13): back insert 13.

[2] ZHANG Su. Research on Training Mode of Competitive Sports Talents in Universities in China. Sports Culture Guide, 2012(4): 92-95.

[3] XU Lei, ZOU Yong. Thinking on Sustainable Development of China's Competitive Sports-Research and Analysis of Development Idea Focusing on Competitive Sports in Universities. Sports Time, 2014(18): 46-47.

[4] GAO Yuan. Research on Sustainable Development of Competitive Sports in Ordinary Universities. Tianjin University, 2012.

[5] CHEN Ying. Research on Schoolization Development of Competitive Sports. Huazhong Normal School, 2013. 